\title{
Implementation of a generic concurrent engineering environment framework for boatbuilding
}

\author{
A.J.Sobey · J.I.R.Blake • R.A.Shenoi
}

Received: date / Accepted: date

\begin{abstract}
Boatbuilding is a growth market with global competition and tight profit margins. Concurrent engineering is not presently prevalent within the boatbuilding industry and yet this is a technique that has found much success in other industries. A methodology has therefore been developed to aid design in the leisure boatbuilding industry. This environment uses collaborative engineering and automated communication to aid the passing of direct communication between all members of the design team. This paper determines the characteristics of importance within boatbuilding and relates these to a framework concurrent engineering environment aimed specifically at this industry. The current work focuses on the structural and production subsystems in an attempt to improve design for production. The use of concurrent engineering tools has been highlighted with an example.
\end{abstract}

Keywords Concurrent Design · Design Automation · Design for Production

\section{Introduction}

Boatbuilders compete in a global market due to an easily transportable product combined with customers who have an ability to visit and appraise the products all over the globe. This leads to competition which, when combined with tight profit margins on relatively small volumes of product, causes the industry difficulties. Further to the difficulties of staying competitive in a "high tech" market, boatbuilders often work with a number of other companies in a large supply chain. It is not unusual practice for the designs to be done in one company, the detail to be developed at another and the production to be carried out elsewhere. This leads to the possibility that the collaborators in the project may not communicate effectively with one another and in some extreme cases may never meet.

A.J.Sobey

University of Southampton, University Rd, Southampton/England, SO17 1BJ

Tel.: +442380 597773

E-mail: ajs502@Soton.ac.uk 
There are significant challenges faced by low volume, high value bespoke luxury vessels with fragmented supply chain support versus those faced in big shipbuilding companies, which typically have greater purchasing power and strategic weight. Fundamentally, the design of these luxury/small vessels are dominated by aesthetics and low deadweight (luxury and volume being their "cargo"). This drives outfitting to take up two/thirds of the total build time and $80 \%$ of the cost making it incomparable to shipbuilding. These problems combine to drive a requirement for low cost concurrent engineering solutions using software that is currently already in use allowing lower training costs. This requires novel structures for and approaches to concurrent engineering.

Concurrent engineering is a process which has benefited many different industries throughout the world. The aim of a concurrent engineering environment is to increase the communication between all members of a company who could add benefit to a design. The attempt to improve this communication can be split into two parts: direct communication between the design engineers and other areas of the company, and automated communication through design tools that help to show the effects that designers have on other areas of the company in making their design decisions. The distributed nature of the boatbuilding industry leads to communication problems while high competitiveness drives a requirement to increase efficiency. Concurrent engineering offers an effective solution to these problems through both communication and work tool development.

This paper therefore looks at the development of a low cost concurrent engineering environment, focusing on automation, with the aim of aiding communication between the different areas of the leisure boatbuilding industry, with an emphasis on the structural and production subsystems. The paper contains an example of the process as it passes between the different automated tools and the concurrent engineering design environment.

\section{Literature Review}

It has been reported that $5-7 \%$ of a product's cost comes from the design and this can have an effect of $70-80 \%$ on the final cost, see [?]. It is therefore important that this process is carried out efficiently while producing the best product possible. [?] describe problem solving, such as in the case of design, as involving "step-by-step analysis and synthesis. In it we proceed from the qualitative to the quantitative, each new step more concrete than the last.". This definition shows the manner in which a design idea must become a fully formed design before being produced. The process is defined in a number of steps by [?]:

- Planning and Task Clarification

- Conceptual Design

- Embodiment Design

- Detailed Design

The first step is to gather the information that is required for the task. Then the constraints of the product must be determined and the task that the final product will undertake decided. This process will hereby by referred to as customer requirements. The next step is the conceptual design during which a principal solution is reached by abstracting the essential problems, establishing function 
structures, searching for suitable working principles and combining those principles into a working setup. The embodiment design constructs the overall layout of the design. Finally the detailed design stage is where the arrangement, forms, dimensions and surface properties of all the individual parts are finally laid down. This process is carried out using a number of different methodologies.

The most well known methodology for the design of ship and other marine structures is the "Design Spiral" presented first by [?].

Within the spiral, shown in fig. 1, design is started with a general arrangement where this subsystem designer carries out initial calculations. The process progresses to include the machinery subsystem designer and through until the weights subsystem designer has completed their work and made design changes. At the end of this first spiral the final design can be evaluated and from here a second spiral can be started where refinements can be made to the original design based upon the changes made by other subsystem designers. A problem that can often occur with this type of design method is that a design decision made by one subsystem designer may have been taken out of the design by the time that one iteration of the process has occurred. This may mean that there is a requirement to replace the current design with the old design, due to its importance to the specified subsystem, therefore slowing down the process and making it harder to reach a compromise between designs. Furthermore from the design spiral given by [?] and shown in fig. 1 it can be seen that production is not specifically taken into account.

The structural design process consists of a concept design and detailed design stages after which point production will begin. Looking more specifically at the structural design a major part of this subsystem will be that of the hull design. For the design of structures a general sequence of actions is defined by [?]:

1. Define initial dimensions of structural element

2. Establish load case

3. Select the strength analysis method

4. Define the allowable deflections, stresses and/or strains

5. Analyse and adjust scantlings for optimum design

In this process an initial determination of the dimensions will be determined from the customer requirements, a load case will be established based upon the type of environment that the vessel is expected to encounter, the strength that is required from this load can then be calculated using constraints based on deflections and stresses. Finally the topology can then be adapted to suit the specific case the boat will be expecting to operate under. It is this process that must be recreated with automated tools to define an optimised first iteration of scantling determinations.

Concurrent engineering is defined as "a systematic approach to the integrated, concurrent design of products and their related processes, including manufacture and support. This approach is intended to cause the developers, from the onset, to consider all elements of the product life cycle from concept through disposal, including quality, cost, schedule and user requirements" by Syan [?]. This definition shows the manner in which different areas of the design process must be integrated together for the design process taking into account a holistic view of the design. Some common key points are Parallel design, Multidisciplinary team, Facility, Software infrastructure and Support and understanding for the environment. 
It is possible to see from previous literature, [?] to [?], the prevalence of concurrent engineering in other industries. Many companies within the aerospace industry also made the transition and found success from Airbus, through Airbus Concurrent Engineering (ACE) [?] and Boeing military aircraft company in 1999 reported in [?]. Astronautics is another industry where concurrent engineering has been used with NASA and ESA developing the Project Design Centre (PDC) at the Jet Propulsion Laboratory in 1994 seen in [?] and Concurrent Design Facility (CDF) at ESTEC in 1998 and reported in [?] respectively. More specifically to the marine industry it can be seen from [?] that many companies within shipbuilding had started to use concurrent engineering. It can be seen that research is now being concentrated upon tools which often fall under the umbrella of concurrent engineering, as seen in [?], including: Integrated Project Teams (IPT), Digital Product Definition (DPD), Digital Pre-assembly/Mock-up (DPA), Computer Integrated Manufacturing (CIM), Lean Manufacturing (LM), Design for X-ability (DFX), Total Quality Management (TQM), Quality Function Deployment (QFD), Supplier Involvement on Product Team (SI), Customer Involvement on Product Team (CI). It is therefore important when developing concurrent engineering to understand the interaction between the different techniques. The combination of these different processes leads to the holistic view integral to concurrent engineering.

Concurrent engineering has had a beneficial effect upon the industries within which it has been used. Due to the prevalence of concurrent engineering in many different fields, shown in references [?] to [?], it is important to understand the similarities and differences between the industries to be able to take the techniques that are most useful in each of the different areas. Table 1, taken from [?], which illustrates the similarities and differences between industrial sectors and has been expanded to include boatbuilding.

From this table it is possible to see that aerospace and shipbuilding applications have many similarities with those of boatbuilding. This is because the volumes of boats are small in comparison to those of the automotive industry. An advantage the aerospace and shipbuilding industries have over boatbuilding are the level of resources that they have available within the companies. It is therefore importan$\mathrm{t}$ that boatbuilding companies have the ability to take advantage of concurrent engineering environments with more limited resources in terms of the cost to implement the environment, the time to train to use it and the smaller number of design and production engineers required in producing a boat. The ability to work together as small-medium sized enterprises (SMEs) will allow these boatbuilding companies to gain greater control over their supply chains allowing competitively priced products more geared towards the marine industry. Table 2, drawn from [?] and [?], shows the gains achieved by shipbuilding and aerospace industries through adopting concurrent engineering principles. Starbek and Grum [?] reiterate this importance of solutions for SMEs having found that the treatment of concurrent engineering in smaller firms should be different to that of larger ones. Beylier et al. [?] further support this view in their work looking at the collaboration within SMEs stating "In small and medium-sized enterprises (SMEs), knowledge management systems cannot be considered in the same way as in large companies."

It can be seen from previous use that concurrent engineering is a design methodology that has been successfully applied to a number of different industries. A number of industries with characteristics similar to boatbuilding are using 
the capabilities from concurrent engineering. This leads to a belief that this system can be used within this sector. It is therefore proposed that a concurrent engineering environment specific to the boatbuilding community will allow an increase in profit margins through an improved design process. The environment would need to be a basic building block upon which the idiosyncrasies of the different companies would need to be able to be catered for. This basic building block could then be populated with a number of automated design tools. It is proposed that the use of automated design tools will allow for increased knowledge transfer aiding to improved designs incorporating more compromise at an earlier stage as supported by [?]. Furthermore with $2 / 3$ [?] of communication being based on content, questions, piece of information, goal related statement etc., automated communication will help reduce some of this traffic. While work continues to develop management frameworks [?] the methodology created here is based around the use of automated design tools with the next section outlining the current state of the boatbuilding community to determine the requirements with the following sections outlining the methodology, environment and tools used to solve the problem of creating a compromise between the structural and production engineers. Previous work has been performed by the authors, [?], [?], [?], [?], [?], [?], [?] and [?], reporting the detail of each tool and some preliminary conclusions of the given methodology. This paper brings together these different areas of research showing how automated design methods can be combined within an overarching methodology for concurrent engineering for boatbuilding and reporting on the environment developed.

\section{Generic Concurrent Engineering Environment Methodology for Boatbuilding}

The methodology of the design has been adapted and extended from the work of Pahl et al. [?]. Fig. 2 shows the manner in which different tools and people are able to relate to the design process and how they communicate with each other. The fig. includes computer systems and storage, which are represented in clear boxes, different people associated with design, production, marketing and the customers themselves, in light grey, tools developed for the environment, in dark grey, and the design studio(s), in diagonal stripes. All of the tools will be available to the design team through access to the virtual concurrent engineering environment which allows communication between the design engineers when they are not in the same real world environment and contains the tools and databases required for effective design. There is also physical space for the design teams which is highlighted in green. This may be in one place but due to the growing requirement for engineers to be split all over the world may represent a number of different locations. Arrows between the different boxes represents the flow of data around the environment.

This process starts with a number of different inputs, sales, customers, materials, supply chain and previous designs all of which can be entered into databases so that the information and data is stored for future use. From the database the concept design starts using Quality Function Deployment as this allows opinions relating to the success of the design to be quantified. This process can be aided by the use of neural networks that can adapt the outputs based on similar successful/unsuccessful designs that have been created previously. This process produces 
weightings of importance for the design that can then be fed into an optimisation with some initial values for the design. This optimisation models the relevant subsystems of the design and produces a design that adheres to the customer requirements. This optimisation produces a starting point for the design which can then be carried out using an iterative design process between different subsystems of design to be created within the concurrent engineering environment. The iterative design process is aided by the system architecture which aims to develop a method for rapid transfer of data and information between the different subsystems. Furthermore communication is aided through the use of reliability which is used to ensure that designs are created in such a manner that there is the most room for error within the production process. The neural networks can be further utilised at this point to ensure that similar designs are found and that the reasons behind failures, successes, changes and new solutions are available to allow communication to be transferred. Finally the production sequence can be optimised for the new design and this stage in the process can be started. A further explanation of each of the tools is given in section 4 .

All of these tools are included within a concurrent engineering environment which is both the physical and virtual design spaces. This environment allows the communication between the different design team members and also allow the different tools to communicate both with the design team and each other environment itself. The design environment has therefore been split into 4 different sections:

- Information transfer

- Data transfer

- Data storage

- Computer hardware

The information transfer has been split into distributed transfer between members of the design team in different locations and also transfer between members of the design team in closer proximity. Data transfer occurs in an automated manner between subsystems of the design. Computer hardware consists of a shared grid computing network for the entire boatbuilding community to increase computational power while reducing maintenance and purchase costs. This system needs to be outsourced to allow for the opportunity to have shared floating licenses. Data storage consists of a number of databases that must be easily accessible and produce information and data that is relevant to the design situation.

For use within the boatbuilding industry it is of key importance that due to the small amount of resources compared to other industries the companies work together to share information in the databases including materials testing allowing a more diverse selection of materials and production techniques to be selected. The system is therefore connected other design teams in other companies. As an example if designer 1 is a structural engineer at company 1 it will be possible to communicate with the hydrodynamics designer, designer 2 , through the use of either an information or data transfer. The data transfer will work in terms of quantitative data and once set up will transfer all changes automatically. The information transfer will be via spoken word, forums and the transfer of pictures, graphs, etc.. It will be possible for the structural designer to communicate with the databases either directly or through the use of neural networks automatically selecting the required information or data. Each method of exchange will be reliant 
upon computers in a consortium grid computing network that will handle computational calculations for the companies. Company 2 will have exactly the same setup sharing the same computational resources and some of the shared databases, others will be entirely independent. The system will be set up to ensure that the private resources of each company can not be shared but the cost of upkeep will be vastly reduced for both companies.

These techniques and the system implemented can be used to further the iteration of the design. For use within British boatbuilding it is important that development costs are kept low and therefore spreadsheets have been linked to allow effective transfer between subsystems as shown in fig. 3 .

During data exchange, data is transferred between subsystem spreadsheets during natural breaks within the design sessions. During periods when the design process is paused the systems can update. This means that design engineers gain updates at least once in a day. The data does not become stagnant and only new data is being used. This combined with design tools that allow rapid development of concepts closer to the final design leads to a reduction in the use of old data. This will ensure that there are no pauses in the concurrent engineering either due to out of date information or subsystems that are slow to start their section of the design. Extending the previous example to show the data exchange:

1. During the design sessions themselves subsystem designers make requests for data they require from other subsystems, as an example the production engineer may request the number of beams in the structure from the structural engineer.

2. The request passes through the data exchange and if the data has already been requested from another subsystem is passed directly back. If not, the request is then passed on to the subsystem from which the data was required. Following the example if the structural engineer has already given the information to another subsystem (the number of beams has already been given to the layout subsystem) this information can automatically be passed back. If not, the next step occurs.

3. After the session break the subsystem to which the data has been requested will receive the request: the structural engineer will now receive a request for the number of beams.

4. During the next session the data can then be passed into the "requested information" spreadsheet. The structural engineer can now reply to the request.

5. At the next design break this data is then passed back to the original subsystem. Any changes to this data will automatically be passed through the system and as such changes to subsystems permeate through the entire design. A link has now been formed: any changes made by the structural engineer will automatically update the production engineer's calculations.

This process of data communication while not being new has been set up to allow for an ability to easily and cheaply change the system. Furthermore the ability to easily attach and customise the tools developed allowing them to gain data from a collective of industrial company databases will allow the maximum effectiveness of those tools. This framework will therefore allow the use of some techniques that may not be available to typical SMEs. 
4 The Design Environment

\subsection{Concept Design}

For the process of concept design two main tools are utilised. The first is Quality Function Deployment which is used within other industries to develop an objective compromise between the customer and the engineer and to focus the design process towards that which the customer requires. Quality function deployment works by comparing customer requirements to design variables. This rates the importance in terms of the relation to each other and their importance to fulfilling the final objectives. A set of technical priorities are developed which are the sum of the design criteria weightings multiplied by the importance of the customer requirements to the design criteria. This allows the design variables to have an importance rating or in this situation allowing a weighting to be created for the genetic algorithm. This therefore means that for an example of a boat hull it might be determined that an optimum of mass and cost could be the important factors to be included. Rather than choosing an arbitrary weighting of 0.5 for each it is possible to find an objective value for these weightings by determining the effect that different factors have on the plate as shown in fig. 4. From this analysis a factor of 0.4 should be applied to the cost and 0.6 for the mass. These results show that the mass should be reduced more than the cost. Neural networks can also be used in this phase to remind engineers of what has been done previously giving an understanding of successful/unsuccessful solutions to problems ensuring that previous unsuccessful concepts are evaluated properly and any similar successful solutions are available for analysis. For example this might indicate that a previous boat design of a similar length was built using the volume fraction of fibre has been built previously but that controlling this volume fraction was difficult and therefore a lower value should be used in the calculations to allow for a safety factor.

\subsection{Design histories}

Design histories are a key part of an evolutionary design process. Previous research has shown that the feedback gained can often be unreliable, delayed, negative and sometimes missing altogether [?]. The boatbuilding industry is particularly reliant upon the use of previous designs to continue brand development and increased marketability due to its evolutionary nature. This means that often successful parts, processes or drafts of one design can be continued on to the next. Further to this even with a lack of prototyping further improvements can be made through assessing similar preceding designs and determining their effectiveness once in operation. This is currently done using 'Design Gurus' who are experienced members of the design team who have been in companies for a long period of time. The addition of shorter contracts and staff who are less likely to remain at one company for the entirety of a career has made this a more difficult process. Further to this as expressed earlier the key to concurrent design is the understanding of and compromise with other subsystems, the process of looking at decisions made on previous designs can aid this understanding. The use of design histories, through data mining and neural networks, that allow this balance to be more easily created by adding in weightings specific to the designer, the type of vessel, the company 
and the entire boatbuilding industry based on previous successful designs. This is in addition to being automatically able to compare potential new parts with those of old designs. For a simple case such as an engine to be fitted into a given volume and requiring a certain power this has been shown, by Sobey et al. [?], to have an accuracy of $95 \%$ given by the number of correct answers from the neural network divided by the number of test values. Furthermore if the requirement for an engine being designed was as shown in fig. 5 a design history could be run, the results of which are shown in fig. 6 . The results show a list of engines that are rated accordingly to be as close to the current requirements as possible and also contain information relating to previous use. Whilst this example rates the choice of engine on a limited number of high level criteria such as overall dimensions other factors could be incorporated such as the reliability of the supplier, performance of the product and cost of acquisition, maintenance and recycling to apply a search that becomes highly complex and relies on a large amount of user knowledge.

\subsection{Structural Optimisation}

Structures are an important part of the design process as it is the determination of the topology of a boat which ensures it is strong enough to withstand the conditions to be met and yet also determine the mass and hence the emissions and performance of a boat when in service. As has been mentioned previously classification society rules are the main method of boat design within yards and therefore both ISO 12215-5 and Lloyd's Register Rules for Special Service Craft have been modelled. Further to this first principles modeling has been continued from [?] to develop a model that allows for a larger range of materials to be developed than are allowed for in these current rules.

For the development of the first principles rules it has been determined that Navier grillage theory is used in association with elastic equivalent properties to model the stiffeners within the boat hull. The plates within these stiffeners have been modelled using third order shear deformation theory. Finally the model has been constrained using failure criteria from the World Wide Failure Exercise, a large review of composite failure criteria reviewing 19 theories over 14 problems, from which were selected the theories by Puck [?], Zinoviev [?] and Tsai [?], with recommendations for their use, as seen in Soden et al. [?], Kaddour et al. [?] and Hinton et al. [?], [?].

The optimisation has been performed using a genetic algorithm approach which is a multiobjective optimisation method that allows fast resolution of results while searching a large search space. Genetic algorithms work by copying the process of DNA transfer in living organisms. They then use the process of evolution to find the optimum solution for a given search space.

Embedded genetic algorithms have been used in the optimisation process as shown in fig. 7 and developed from Coley [?]. The main genetic algorithm is used to optimise the stiffener spacing in both the longitudinal and transverse directions, the material type and layup angles. The embedded algorithm is used to determine the optimal geometry of the stiffeners through creation of the crown width and thickness as well as the web height and thickness. This means that the embedded algorithm develops an optimal stiffener geometry with respect to mass and cost for each given stiffener spacing and material property generated in the main al- 
gorithm. The main algorithm then determines the reaction for the total grillage and compares these grillages over many generations until the optimal topology is found.

The constraints for these different properties are shown in Table 3 and the characteristics of the genetic algorithm are listed in Table 4.

This optimisation allows a starting point for the structural designer and allows a knowledge of how different the design is from the optimum after compromise with other subsystems. It can therefore be a reference point for the continuation of the design. Due to the limited number of models, production and structures, this is an initial starting point that starts with a compromise between two subsystems creating a manufacturable hull form that is structurally integral from which changes can be explored. Table 3 shows the constraints that are used for the optimisation on the left. The results of the optimisation can then be run and furthermore these results can be rapidly analysed using Ansys to ensure that the analytical methods used are producing viable hull shapes.

Results from these optimisation results have been previously developed by Sobey et al. [?], [?], [?] and [?] further illustrating the method and showing preliminary results. These results show that the optimisation process can be utilised within a design scenario but that it is of key importance for the production models to accurately replicate the processes to be used for the production. The stiffener topology for the case study shown here, using the weighting from the Quality Function Deployment, are therefore shown in Table 5.

The topology for the plate can then be seen in Table 6 .

\subsection{Production Modelling}

An important part of optimising the structures of a boat hull is the cost that is incurred in building the hull itself as seen in [?]. It is therefore be important to produce an accurate cost model so that geometries of the structures are not optimum only from a structural basis. There are a number of ways to do the costing of a production method depending on the complexity required. The first of these is analogous cost modeling which is dependant on using other vessel costs to give an estimate of the cost based on the fact that models that are similar to each other. Parametric costing is done by creating relationships between different parts of the vessel and the cost that these will create dependant upon the size of the part. Finally detailed cost analysis is based upon a more in depth understanding of the materials, manufacturing techniques etc. that are involved. Production modelling does change from yard to yard and as such the models change for each company. To fully utilise optimisation it is important to get an understanding of the production model and move away from the general parametric model to that of a specific detailed cost model. A cost model for a composite leisure boat used for the optimisation process can be seen in Table 7 with the adjustments made to incorporate stiffeners in Table 8. A cost model for composite boatbuilding has been developed. Previous work by Sobey et al. [?] has shown that these models must be detailed to ensure that the results from optimisation is valid. Production models that do not accurately represent a detailed model for the production have been shown to develop erroneous results. 


\subsection{Reliability}

Reliability methods are becoming an ever more important of structural design through the ability to be able to model variation within the production of a given object. Reliability methods allow for a prediction of a given situation, often probability of failure in the case of structures, based on statistical inputs for the different characteristics of the object. Reliability methods have been used to communicate between the areas of structures and production. Through charting the changes in the probability of failure or cost of a product it is possible to use Monte Carlo simulations to give insights into the behaviour of other subsystems of design from changes made in the engineers own subsystem. This allows a more intuitive understanding of other subsystems of design. By studying the manner in which changes in coefficient of variation of the inputs effect the output probability it allows an easy and intuitive understanding of the manner in which changes made may effect other subsystems. This allows designs to be created that have a robust structure allowing a low production cost. From the scantling produced in subsection 4.3 the probability of failure can be determined as $7.76 \times 10^{-5}$. Checking this reliability factor against DNV rules [?] this is a "safe" reliability and falls in the region of "rare" to "not of great concern to the average person". Through further analysis, we can determine the parts of the structure and the associated design variables that are prone to change the reliability index owing to variations in the value and spread of those variables. These results show that the breadth of the plate, Youngs modulus of the E-glass fibres and the volume fraction are the most important. This requirement means that an increase in breadth or a decrease in the other values should not be made by the production engineer. From these results it is possible to see that the transverse web and crown heights can be created faster and with a lower accuracy, to reduce cost, as these parts are less structurally integral and that the longitudinal stiffeners are more important than the corresponding transverse ones. From the optimisation of the cost and mass initial scantlings have been determined. The reliability analysis then gives the designer an idea to the probability of failure of the plate and a better understanding for how changes made to the hull may effect the mass and the cost. Further to this as a first principles approach has been used, whereby the first principles calculations have been constrained using failure criteria without the introduction of phenomenological additions or safety factors, safety factors have been derived for a predetermined probability of failure for the part. These values are shown in fig. 8 which shows the sensitivity results, the amount by which an input variable affects the reliability of the structure, for the stiffeners and from these the safety factors and the final dimensions required for a panel with a probability of failure of $10 \times 10^{-6}$. From here an iterative design process is be required incorporating a larger number of factors this is done through the design histories tool and the design environment.

Reliability analysis has been developed that allows for the analysis of composite plates, the methodology for which has been incorporated within Sobey et al. [?]. These results show that a reliability analysis can be an important part of a structural analysis through a comparison between first principles and classification society methods. Sensitivity analysis are also investigated to determine the importance of different variables to the structural integrity of the final product. Further to this work Sobey et al. [?] have used these models developed to generate a reliability analysis of the production models. This has allowed these tools to be 
used to determine which aspects of the design should be investigated dependant on the sensitivity of the cost to those variables.

\section{Conclusions}

A framework methodology for a concurrent engineering environment specific to the needs and requirements of the leisure boatbuilding industry has been developed. The methodology allows reliance on automated communication tools to utilise the strengths of the boatbuilding industry creating the capability to share this knowledge. To use the full capability of new tools that are being developed and to continue prosperity working together as an industry will become more vital to success. The ability to share costs allows the use of technology and software previously unattainable to be used within the design process. Furthermore the increased communication within the industry should lead to large benefits in the future most noticeably a larger control over the supply chain. The success of the boatbuilding industry due to its small size and smaller assets can be improved through the sharing information in a careful manner so as to avoid giving away valuable information giving a competitive edge to industry. The ability for the companies to work together will allow the industry to compete within the supply chain for an ability to choose and develop products more carefully targeted towards boatbuilding.

The development of automated systems allows the environment to be used with greater ease in an attempt to reduce a situation where feedback from past designs is no longer unreliable, delayed, negative or missing altogether and compromise can be increased and used at an early stage in the design. Tools such as optimisation allows the design to start at a point further down the design spiral allowing time to be saved. Furthermore, through the use of reliability techniques and design histories, it is possible for engineers to gain a greater understanding of the other subsystems of the design and to comprehend and use decisions made on previous designs. The ability to transfer this information without direct communication allows a large quantity of knowledge to be transferred while keeping the same amount of direct communication. Furthermore this direct communication can then be used on the development of new ideas and creative solutions to problems. This system help to ensure that knowledge gained from previous mistakes is not repeated. The relationship between these automated tools has been shown with an example created from the design of a boat hull.

Finally the environment has been based upon concurrent engineering systems that are currently used within other industries but developed with low cost or open source software where possible. Furthermore all of the environment has been developed in an easily adaptable manner to allow an easy evolution as new technologies and software are developed and used. This environment has been created to allow for use within companies in isolation or adaptable to allow use by multiple companies to allow use with consultants or knowledge sharing throughout the industry. More research must be performed in this area to expand the tool set available to maximise the potential for small SMEs to successfully perform Concurrent Engineering addressing the balance between design philosophies and techniques developed for large companies. These tools must remain cost effective 
and utilise those tools already common within boatbuilding to ensure take up within the industry and to reduce expensive training costs.

\section{References}

1. K.G. Swift and N.J. Brown. Implementation strategies for design for manufacture methodologies. Proc. Instn Mech. Engrs Part B: J. Engineering Manufacture, vol. 217, 2003.

2. G. Pahl, W. Beitz, K. Wallace, and L. Blessing. Engineering Design: a systematic approach. Springer, 2007.

3. J.H. Evans. Basic design concepts. Journal of the American Society of Naval Architects, vol. 71 :pp. $671-678,1959$.

4. A.R. Claughton, J.F. Wellicome, and R.A. Shenoi. Sailing Yacht Design: Theory. Addison Wesley Longman Limited, Essex, England, 1999.

5. C.S. Syan. Concurrent Engineering - Concepts, implementation and practice. Chapan and Hall, London, UK, 1994.

6. R. Haas and M. Sinha. Concurrent engineering at airbus: A case study. International Journal of Manufacturing Technology and Management, vol. 6(3/4):pp.241 - 253, 2004.

7. M.A. Eaglesham. A Decision Support System for Advanced Composites Manufacturing Cost Estimation. PhD thesis, Virginia Polytechnic Institute and State University, 1998.

8. R. Shishko. The proliferation of pdc-type environments in industry and universities. Proceedings of the 2nd EUSEC, Munich, 2000.

9. S. Finkel, M. Wilke, H. Metzger, and M. Wahnfried. Design centers - transferring experience from astronautics to aeronautics. Proceedings of the 12th Annual Symposium of INCOSE International Council on Systems Engineering, Las Vegas, 2002.

10. M. Bandecchi, B. Melton, B. Gardini, and F. Ongaro. The esa/estec concurrent design facility. Proceeding of EuSec, 2000.

11. G. Bennet and T. Lamb. Concurrent engineering: Application and implementation for shipbuilding. Journal of Ship Production, vol. 12(2):pp.107-125, 1996.

12. M. Gwyther. It worked for fridges! - why shipbuilding needs an industry-specific plm solution. 13th International Conference on Computer Applications in Shipbuilding (ICCAS), Portsmouth, UK, 2007.

13. M. Starbek and J. Grum. Concurrent engineering in small companies. , International Journal of Machine Tools and Manufacture, vol. 42:pp. 417-426, 2002.

14. C. Beylier, F. Pourroy, F. Villeneuve, and A. Mille. A collaboration-centred approach to manage engineering knowledge: a case study of an engineering sme. Journal of Engineering Design, vol. 20:pp. 523-542, 2009.

15. M L. Chiu. An organizational view of design communication in design collaboration. Design Studies, vol. 23:pp. 187-210, 2002.

16. J. Stempfle and P. Badke-Schaub. Thinking in design teams - an analysis of team communication. Design Studies, vol. 23:pp. 473-496, 2002.

17. B.S. Jang, B.H. Kallak, C-H. Lee, D-E. Ko, Y-S. Suh, and Y-S. Yang. A process-centric ship design management framework. Journal of Marine Science and Technology, vol. 15:pp. 23-33, 2010 .

18. A.J. Sobey, J.I.R. Blake, and R.A. Shenoi. Optimization of composite boat hull structures. Computer and Information Management Applications for Shipbuilding (COMPIT), Liege, pages pp.502-515, 2008.

19. A.J. Sobey, J.I.R. Blake, and R.A. Shenoi. Optimisation approaches to design synthesis of marine composite structures. Schiffstechnik - Ship Technology Research, page Accepted for publication, 2009.

20. A.J. Sobey, J.I.R. Blake, and R.A. Shenoi. Optimisation of composite boat hull structures as part of a concurrent engineering environment. In High Performance Marine Vehicles, Naples, pages 133-146, 2008b.

21. A.J. Sobey, J.I.R. Blake, and R.A. Shenoi. Concurrent design and optimisation of frp boat structures. In Design Construction and Operation of Super and Mega Yachts, Genoa, Italy, 2009.

22. A.J. Sobey, J.I.R. Blake, and R.A. Shenoi. Design for production in frp boats. International Conference on Composite Materials (ICCM) 2009, Edinburgh, UK, 2009.

23. A.J. Sobey, J.I.R. Blake, and R.A. Shenoi. Design histories for enhanced concurrent structural design. In International Conference on Computer Science and Engineering, (ICCSE), Malaysia, 2009. 
24. A.J. Sobey, J.I.R. Blake, and R.A. Shenoi. Optimisation of frp structures for marine vessel design and production. In 28th International Conference on Ocean, Offshore and Arctic Engineering (OMAE), Hawaii, USA, 2009.

25. A.J. Sobey, J.I.R. Blake, and R.A. Shenoi. Stochastic methods used in design optimisation of composite boat hull topologies. In Light Weight Marine Structures (LIWEM), Glasgow, 2009.

26. J.S. Busby. The neglect of feedback in engineering design organisations. Design Studies, vol. 19:pp. 103-117, 1997.

27. K. Maneepan, R.A. Shenoi, and J.I.R. Blake. Genetic algorithms (gas) based optimisation of frp composite plated grillages in ship structures. Transactions of The Royal Institution of Naval Architects Part A: International Journal of Maritime Engineering, vol. 149:1-19, 2007.

28. A. Puck and H. Schurmann. Failure analysis of frp laminates by means of physically based phenomenological models. Composites Science and Technology, vol. 58:pp.10451067, 1998.

29. P.A. Zinoviev, S.V. Grigorviev, O.V. Lebedevab, and L.P. Tairova. The strength of multilayered composites under a plane-stress state. Composites Science and Technology, vol. 58, 1998.

30. K. Liu and S.W. Tsai. A progressive quadratic failure criterion for a laminate. Composites Science and Technology, vol. 58:pp.1023-1032, 1998.

31. P.D. Soden, A.S. Kaddour, and M.J. Hinton. Recommendations for designers and researchers resulting from the world-wide failure exercise. Composites Science and Technology, vol. 64:pp.589-604, 2004.

32. A.S. Kaddour, M.J. Hinton, and P.D. Soden. A comparison of the predictive capabilities of current failure theories for composite laminates: additional contributions. Composites Science and Technology, vol. 64:pp.449-476, 2004.

33. M.J. Hinton, A.S. Kaddour, and P.D. Soden. Evaluation of failure prediction in composite laminates: background to 'part b' of the exercise. Composites Science and Technology, vol. 62:pp.1481-1488, 2002.

34. M.J. Hinton, A.S. Kaddour, and P.D. Soden. Evaluation of failure prediction in composite laminates: background to 'part c' of the exercise. Composites Science and Technology, vol. 64:pp.321-327, 2004.

35. D.A. Coley. An introduction to Genetic Algorithms for Scienctists and Engineers. World Scientific, 2001.

36. DNV. Design of offshore steel structures load and resistance factor design method. Technical Report OSC101, Oslo, 2000. 


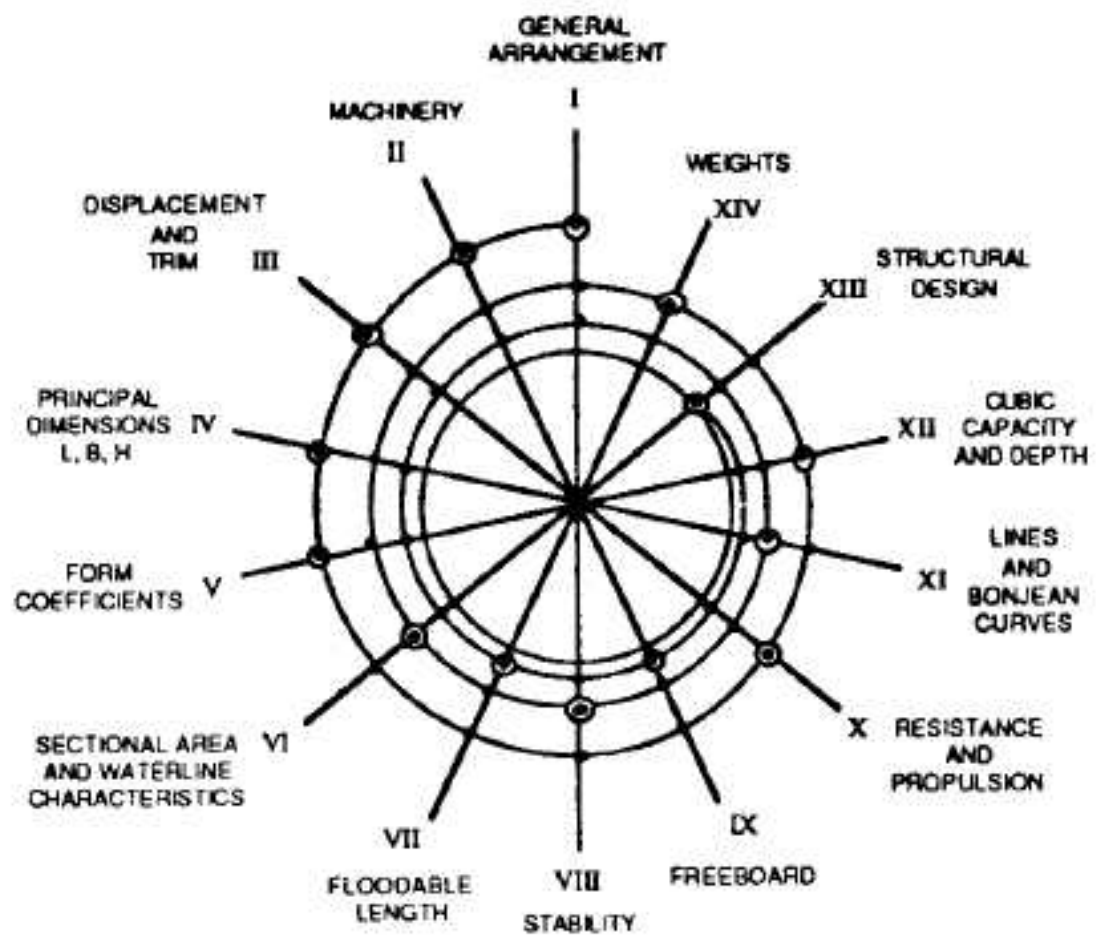

Fig. 1 Design Spiral as Presented by Evans [?]

Table 1 Comparison of Industry Characteristics

\begin{tabular}{|c|c|c|c|c|}
\hline Characteristic & Shipbuilding & Aerospace & Boatbuilding & Automotive \\
\hline $\begin{array}{c}\text { Production } \\
\text { Facilities }\end{array}$ & $\begin{array}{c}\text { Few } \\
\text { simultaneous }\end{array}$ & $\begin{array}{c}\text { Few } \\
\text { simultaneous }\end{array}$ & $\begin{array}{c}\text { Few } \\
\text { simultaneous }\end{array}$ & $\begin{array}{c}1000 \text { 's } \\
\text { simultaneous }\end{array}$ \\
\hline $\begin{array}{c}\text { Development } \\
\text { Process }\end{array}$ & $\begin{array}{c}\text { Concurrent design } \\
\text { Production }\end{array}$ & $\begin{array}{c}\text { Design Prototype } \\
\text { Custom manufacture }\end{array}$ & $\begin{array}{c}\text { Straight to production } \\
\text { Custom Manufacture }\end{array}$ & $\begin{array}{c}\text { Design prototype } \\
\text { Bulk manufacture }\end{array}$ \\
\hline $\begin{array}{c}\text { Design } \\
\text { Collaboration }\end{array}$ & Real time & Pre-production & Pre-production & Pre-production \\
\hline
\end{tabular}

Table 2 Concurrent Engineering in Shipbuilding

\begin{tabular}{|c|c|c|}
\hline Characteristic & Change & Aerospace Change \\
\hline Development time & $30-70 \%$ reduction & $50 \%$ reduction \\
\hline Engineering changes & $65-90 \%$ reduction & $50 \%$ reduction \\
\hline Time to market & $20-90 \%$ reduction & \\
\hline Overall quality & $200-600 \%$ improvement & \\
\hline Productivity & $20-110 \%$ improvement & \\
\hline Dollar sales & $5-50 \%$ improvement & \\
\hline Return on assets & $20-120 \%$ improvement & \\
\hline Cost Saving & & $\$ 68 \mathrm{M}$ reduction \\
\hline
\end{tabular}




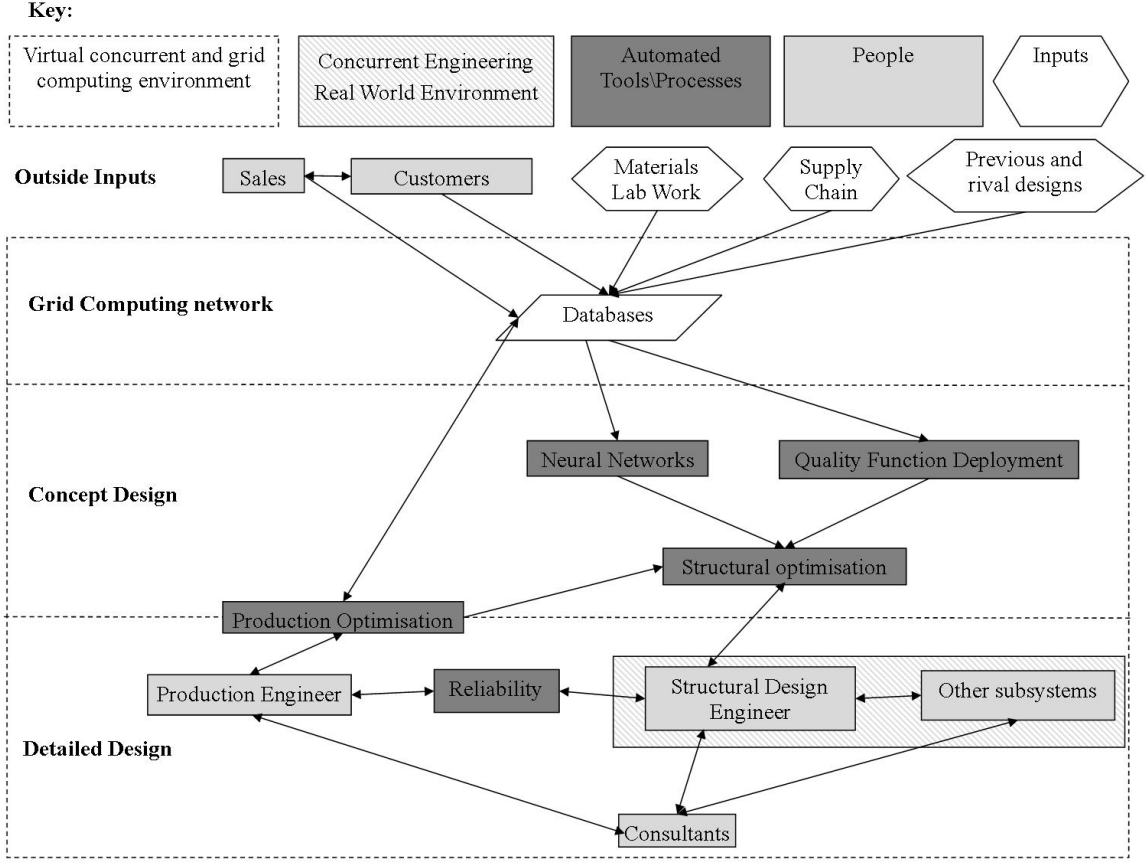

Fig. 2 Design Relationships

Table 3 Genetic Algorithm Constraints

\begin{tabular}{|c|c|c|c|}
\hline Property & Bounds & Property & Bounds \\
\hline Long. Stiffener Spacing & $0-10230 \mathrm{~mm}$ & Ply Angles & 0,90 \\
\hline Trans. Stiffener Spacing & $0-2046 \mathrm{~mm}$ & Ply Materials & E-glass, Aramid, Carbon, HM Carbon \\
\hline Number of Plies & $0-32$ & Long. Crown Width & $0-102.3 \mathrm{~mm}$ \\
\hline Long. Crown Height & $0-20.46 \mathrm{~mm}$ & Long. Web Width & $0-20.46 \mathrm{~mm}$ \\
\hline Long. Web Height & $0-102.3 \mathrm{~mm}$ & Trans. Crown Width & $0-102.3 \mathrm{~mm}$ \\
\hline Trans. Crown Height & $0-20.46 \mathrm{~mm}$ & Trans. Web Width & $0-20.46 \mathrm{~mm}$ \\
\hline Trans. Web Height & $0-102.3 \mathrm{~mm}$ & Plate Thickness & $0-102.3 \mathrm{~mm}$ \\
\hline Stiffener Base Width & $0-102.3 \mathrm{~mm}$ & Stiffener Base Width & $0-102.3 \mathrm{~mm}$ \\
\hline
\end{tabular}

Table 4 Genetic Algorithm Characteristics

\begin{tabular}{|c|c|}
\hline Generations & 200 \\
\hline Strings & 100 \\
\hline Mutation Rate & 0.002 \\
\hline Crossover Rate & 0.65 \\
\hline Selection Method & Tournament \\
\hline Crossover Method & Uniform \\
\hline
\end{tabular}




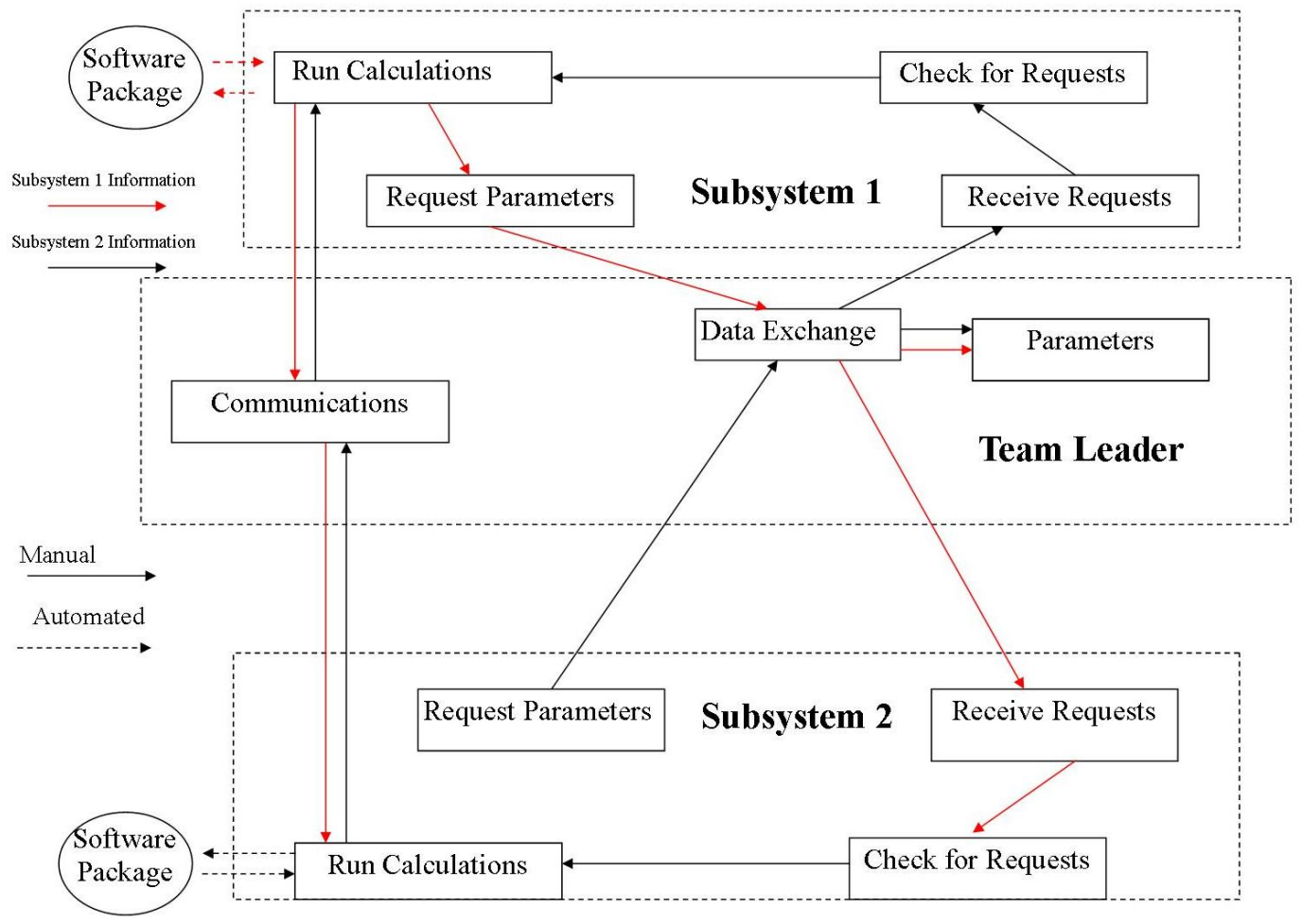

Fig. 3 Data transfer between two subsystems

Table 5 Stiffener Topology for Case Study

\begin{tabular}{cccccc}
\hline Stiffener Type & $\begin{array}{c}\text { Web } \\
\text { Height }\end{array}$ & $\begin{array}{c}\text { Web } \\
\text { Thickness }\end{array}$ & $\begin{array}{c}\text { Crown } \\
\text { Width }\end{array}$ & $\begin{array}{c}\text { Crown } \\
\text { Thickness*Width }\end{array}$ & Base \\
\hline Longitudinal & $79.3 \mathrm{~mm}$ & $2 \mathrm{~mm}$ & $11.1 \mathrm{~mm}$ & $10.94 \mathrm{~mm}$ & 101.4 \\
Transverse & $64 \mathrm{~mm}$ & $1.98 \mathrm{~mm}$ & $92.7 \mathrm{~mm}$ & $3.84 \mathrm{~mm}$ & 62.7 \\
\hline
\end{tabular}

Table 6 Plate Topology for Case Study

\begin{tabular}{|c|c|c|c|c|}
\hline & $\begin{array}{c}\text { Longitudinal } \\
\text { Stiffener Spacing }\end{array}$ & $\begin{array}{c}\text { Transverse } \\
\text { Stiffener Spacing }\end{array}$ & $\begin{array}{c}\text { Plate } \\
\text { Thickness }\end{array}$ & Layup \\
\hline Plate Topology & $390 \mathrm{~mm}$ & $2200 \mathrm{~mm}$ & $3.3 \mathrm{~mm}$ & $90 / 0 / 0 / 0 / 90 / 90$ \\
\hline
\end{tabular}




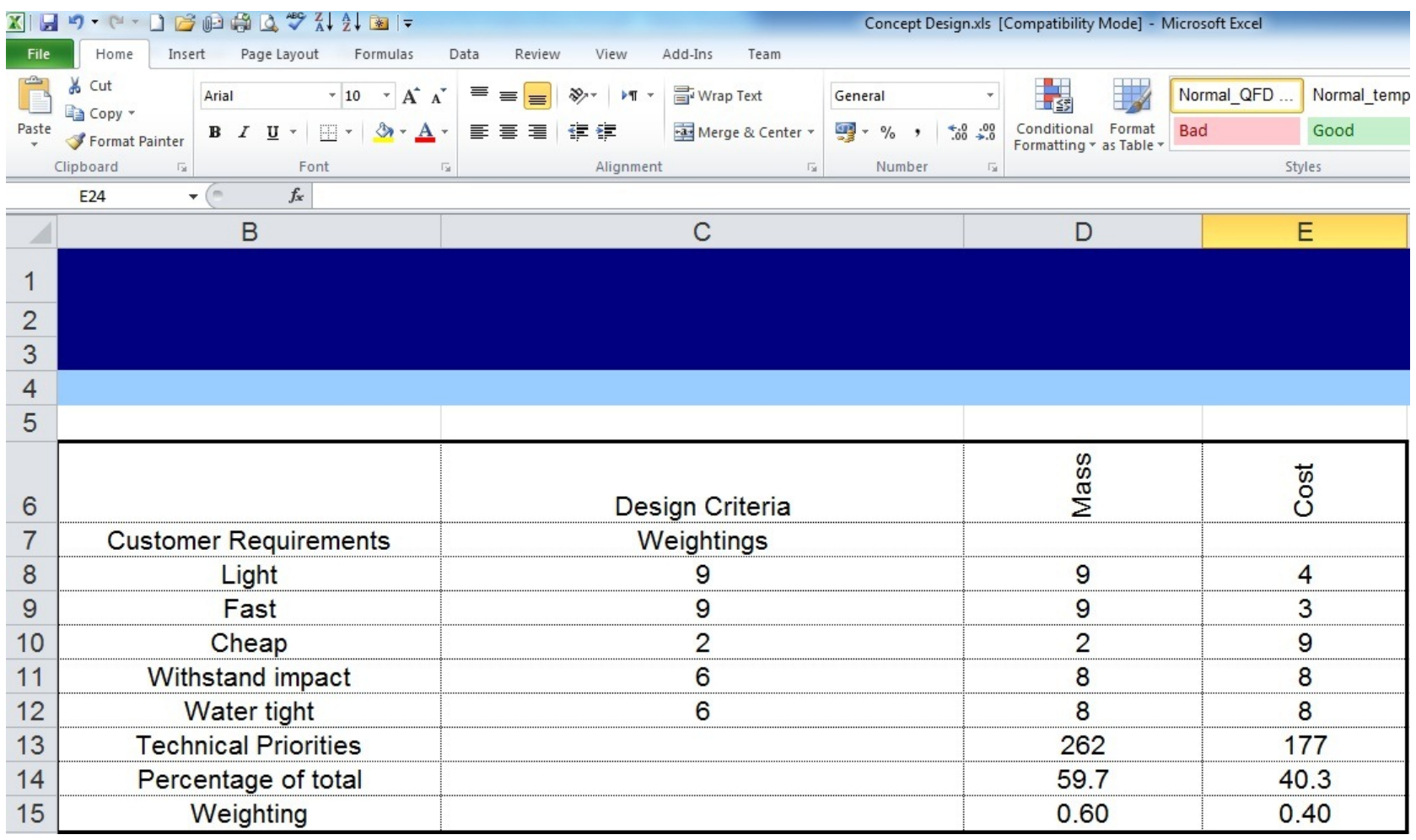

Fig. 4 Screenshot of example QFD

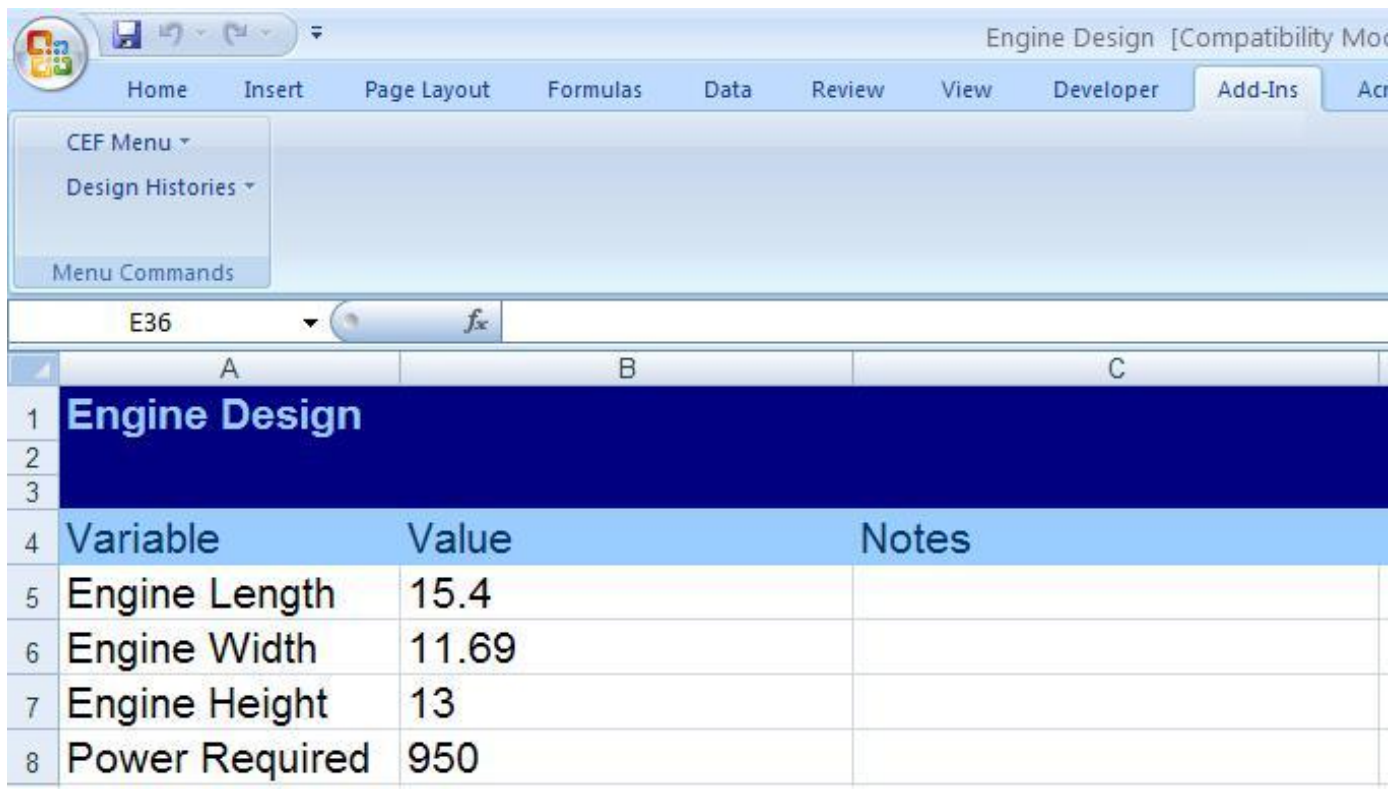

Fig. 5 Screenshot of engine requirements 


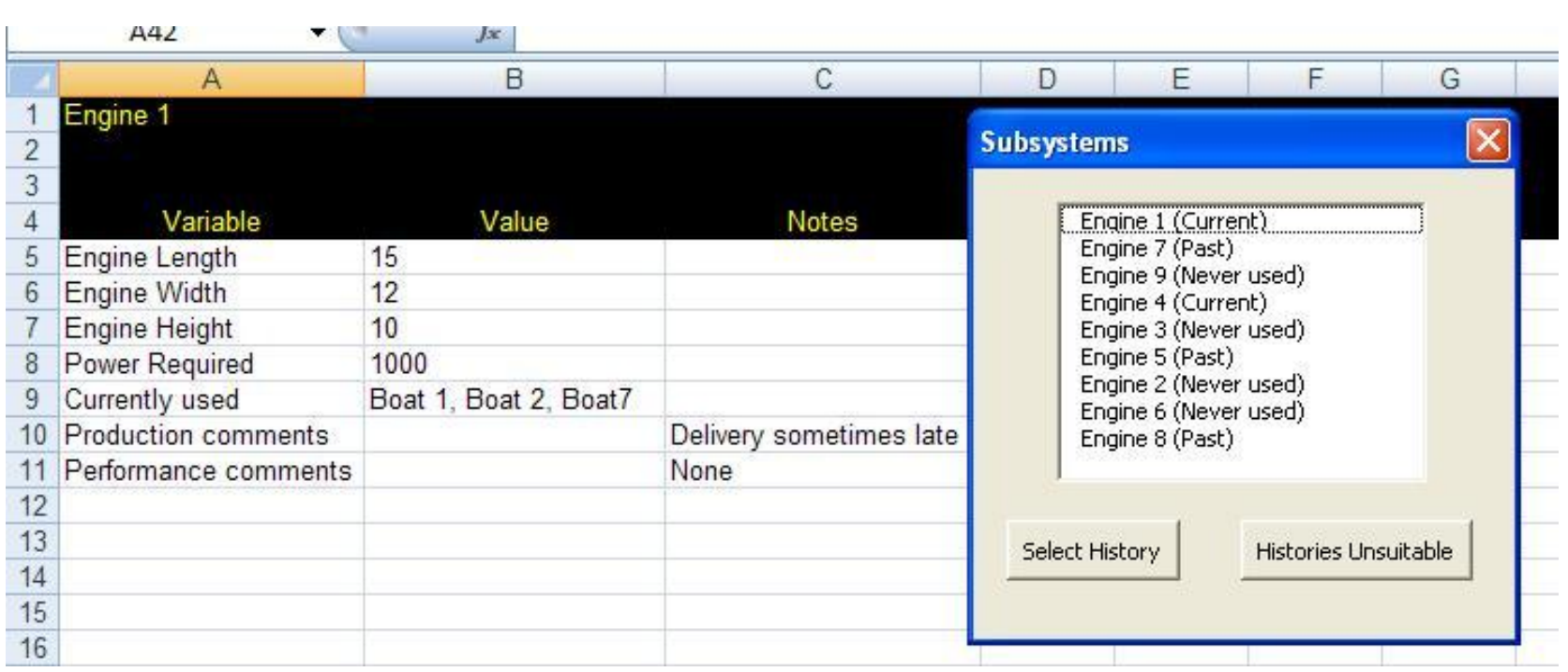

Fig. 6 Screenshot of closest engines available with related data

Table 7 SSA Hand layup Production Model

\begin{tabular}{|l|c|}
\hline Action & Time(mins) \\
\hline Fairing Compound & 10 minutes $/ \mathrm{sqm}$ \\
\hline Smoothing Fairing Compound & 60 minutes $/ \mathrm{sqm}$ \\
\hline Apply Release Compound & 10 minutes $/ \mathrm{sqm} / \mathrm{ply}$ \\
\hline Cutting cloth & $10 \mathrm{minutes} / \mathrm{sqm} / \mathrm{ply}$ \\
\hline Laying cloth & $5 \mathrm{minutes} / \mathrm{sqm} / \mathrm{cloth}$ \\
\hline Cutting and laying core & $60 \mathrm{minutes} / \mathrm{sqm} / \mathrm{core}$ \\
\hline Apply resin with brush or roll & $10 \mathrm{minutes} / \mathrm{sqm}$ \\
\hline Remove the components from the mould & $30 \mathrm{minutes} / \mathrm{sqm}$ \\
\hline Quality Inspection & 3 minutes $/ \mathrm{sqm}$ \\
\hline Trim & 15 minutes $/ \mathrm{m} / \mathrm{edge}$ \\
\hline
\end{tabular}

Table 8 Stiffener cost model

\begin{tabular}{|l|c|}
\hline Action & Cost(mins) \\
\hline Cutting cloth & 10 minutes/sqm/ply \\
\hline Laying cloth & 5 minutes/sqm/cloth \\
\hline Cutting and laying core & 60 minutes/sqm/core \\
\hline Apply resin with brush or roll & 10 minutes/sqm \\
\hline
\end{tabular}


Main Genetic Algorithm:-

Variables: Longitudinal and transverse stiff-

ener spacing's, material type and ply angle.

Output: Optimised stiffener spacing and

material layup

Embedded Genetic Algorithm:-

Variables: Longitudinal and transverse stiff-

eners, crown widths, crown heights, web

widths and web heights.

Output: Optimised stiffener geometry

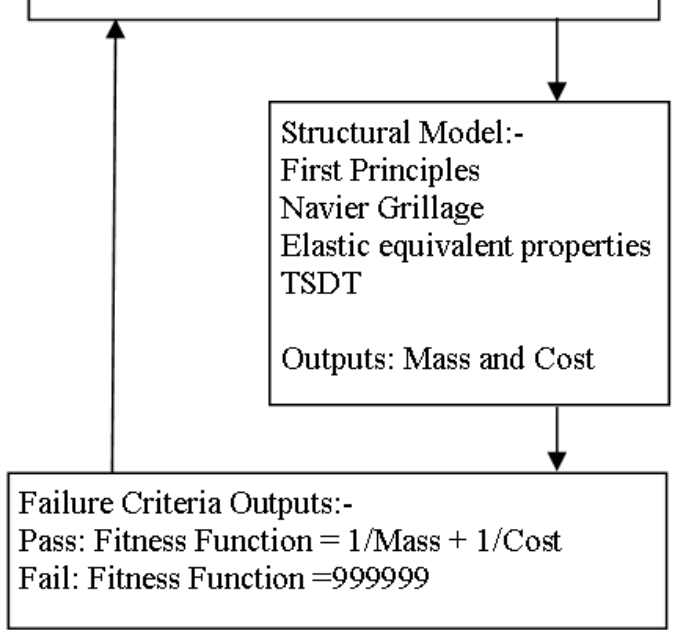

Fig. 7 Genetic Algorithm Flow Diagram 


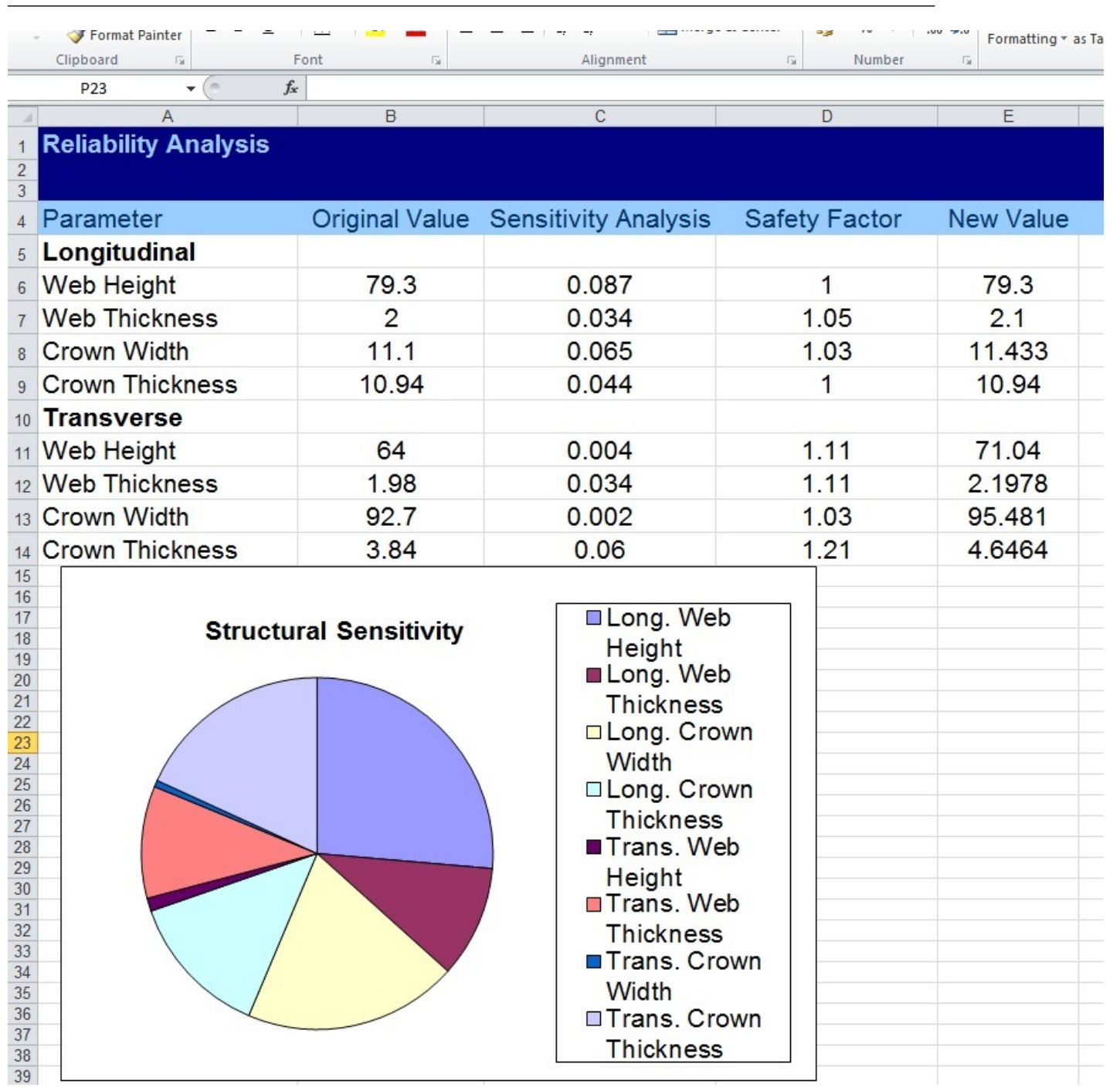

Fig. 8 Screenshot of reliability analysis 